\title{
COLLETOTRICHUM FALCATUM CAUSING RED ROT IN SUGARCANE: GENOMIC AND PROTEOMIC APPROACHES TO CHARACTERIZE THE PATHOGENIC VARIATION
}

\author{
P. Malathi, K. Kaverinathan, M. Scindiya, E. Elamathi, A. Ramesh Sundar \\ and R. Viswanathan*
}

\begin{abstract}
Red rot caused by Colletotrichum falcatum, is the major constraint in sugarcane production in India and varietal resistance plays an important role in managing the disease. However, breakdown of resistance in sugarcane varieties to new pathogen variants which co-evolve concurrently is a serious concern and warrants a clear understanding on pathogenic variation in response to virulence. Hence, a detailed study has been carried out through genomic and proteomic approaches to characterize representative group of $C$. falcatum pathotypes and isolates varying phylogenetically based on 5.8S-ITS sequence analysis. At genomic level the isolates were characterized using conserved gene sequences viz., actin, calmodulin and GPDH and molecular markers viz., RAPD and ISSR. Molecular analyses with conserved gene sequences highly implicated the existence of one major group of virulent isolates and a minor group of least virulent isolates which was confirmed by definite nucleotide variation. Further studies with molecular markers viz., RAPD and ISSR also confirmed separate grouping of least virulent isolates and different groups among the virulent isolates. Among the markers, ISSR was more efficient in grouping the isolates based on virulence, since it clearly differentiated the least virulent isolates like conserved sequences and some of its primers were able to differentiate the virulent isolates with specific markers. For proteomic analysis, a protocol has been standardized to develop $C$. falcatum proteome profiles of phylogenetically differentiated virulent and least virulent isolates and demonstrated unique and differential expression of spots related to pathogen virulence. Some of the unique proteins viz., serine protease, DJ-1/PfpI family protein and glutathione S-transferase identified from $C$. falcatum were closer to well characterized pathogenicity related genes in Colletotrichum spp and other fungi. Outcome of the study formed a basis for characterizing virulence related genes in $C$. falcatum.
\end{abstract}

Keywords: Colletotrichum falcatum, conserved genes, molecular markers, proteome profile

\section{Introduction}

Sugarcane is an important field crop grown in almost all the states in India and seed transmissible red rot caused by the fungal pathogen Colletotrichum falcatum Went (Teleomorph: Glomerella tucumanensis (Speg.) Arx and Muller) is one of the most destructive diseases of sugarcane in the country. Severe red rot epidemics occurred in different parts of the country during the last century led to the elimination of several elite sugarcane varieties and the emerging new variants of the pathogen were responsible for the breakdown of released resistant varieties (Viswanathan 2010). Major pathotypes used in screening programme were distinguished at morphological, cultural, pathogenicity, serological, genetic and molecular level tocertain extent(Malathi etal.2010; Mohanraj et al. 2002; Suman et al. 2005; Viswanathan et al. 2003). Further, our phylogenetic study with $75 C$. falcatum isolates based on 5.8S-ITS revealed that

P. Malathi, K. Kaverinathan, M. Scindiya, E. Elamathi, A. Ramesh Sundar and R. Viswanathan*

Division of Crop Protection, ICAR-Sugarcane Breeding Institute, Coimbatore - 641 007, Tamil Nadu, India

*Corresponding author: rasaviswanathan@yahoo.co.in

Submitted: 26 February 2020; Accepted: 29 March 2020 
there were two major groups comprising of $95 \%$ isolates with virulent nature and one minor group with 5\% isolates of least virulent nature (Malathi et al. 2011). Gene sequences for conserved proteins are used extensively in phylogenetic studies along with ITS data to reveal the genetic variation in understanding and to explore evolutionary relationship in the fungal taxonomy (Guerber et al., 2003; Hirata et al. 2007; Whitelaw-Weckert 2007).

Apart from ITS gene sequences, molecular markers could be used to characterize the isolates for phylogenetic grouping. There are different kinds of markers viz., RFLP, AFLP, RAPD, SSR, ISSR etc. and each one has its advantages and disadvantages. Since random amplified polymorphic DNA(RAPD) has been used in earlier studies for characterizing C. falcatum isolates, RAPD was compared with recent widely used inter simple sequence repeats (ISSR) markers.

Moreover it is understood from the earlier studies that the $C$. falcatum isolates vary in the production of various pathogenicity determinants viz., enzymes, toxin and melanin (Malathi and Viswanathan, 2012; Kaverinathan et al. 2017) and responsible for expression of various pathogenicity related genes during its pathogenesis (Scindiya et al. 2017). Hence, further research is needed to characterize the genes/ proteins related to pathogenicity factors of C. falcatum. In recent years, 2-dimensional gel electrophoresis (2-DE) has been widely used to study the proteome of phytopathogenic fungi and this approach is useful in obtaining the proteomic maps of disease causing fungi which will be highly useful to compare and identify unique and differentially expressed proteins between isolates varying in virulence. Results from fungal proteomic studies showed that it is a potential tool for identifying pathogenicity factors, therapeutic targets and for basic research (FernandezAcero et al., 2007). Reports indicated that 2-DE has been effectively utilized for comparative analysis of mycelial protein and secretomes in basidiomycete fungi (González-Fernández et al. 2014; Alfaro et al. 2014).

With this background, the present study on genomic approach was carried out to appraise the feasibility of utilizing nucleotide sequences of conserved genes viz., actin, calmodulin and glyceraldehyde 3-phosphate dehydrogenase (GPDH) along with 5.8S-ITS to confirm their molecular grouping in a representative group of C. falcatum isolates. Besides, molecular markers viz., RAPD and ISSR were used to confirm the existence of least virulent isolates in the group and possibility of identifying suitable marker linked to any specific trait related to virulence, origin etc. Furthermore, phylogenetically differentiated virulent and least virulent isolates were selected and utilized in proteomic approach for identification of proteins related to C. falcatum pathogenicity. In this context, preliminary attempt has been made to standardize the protocol to develop proteome profiles of genetically distinct isolates to characterize unique/ differentially expressed proteins in relation to pathogen virulence.

\section{Materials and Methods}

\section{C. falcatum isolates}

Sixteen C. falcatum isolates representing three groups of ITS based phylogenetic analysis (Malathi et al. 2011) were selected for validation with conserved gene sequences and molecular markers, finally selected two extremely varied isolates in response to virulence and studied differential expression of proteins. For this purpose, 10 designated pathotypes viz., CF01- Cf1148(H1), CF02 - Cf7717(H2), CF03 - Cf64(H3), CF04 - Cf419(AP1), CF05 - Cf997(AP2), CF06 Cf671(TN1), CF07- Cf64(H5), CF08 - Cf64(H6), CF09 - Cf767(H7) and CF10 - Cf89V74(AP11) selected under differential interaction studies in 
both tropical and sub-tropical conditions were employed. Besides some of the isolates viz., Cf92061(TN3), Cf90063(TN5) and Cf64 always showing virulent reaction and some of the isolates viz., Cf94101, Cf86032 and Cf92020 belonging to least virulent group for a long period were also included for comparison.

\section{PCR amplification and sequencing for conserved genes}

Genomic DNA from fungal cultures were extracted based on CTAB method and subjected to PCR amplification with 5.8s rDNA-ITS region and other conserved genes viz., actin, calmodulin, and Glyceraldehyde 3-phosphate dehydrogenase (GPDH) gene sequences. The amplified products were purified and sequenced to study nucleotide variation among virulent and least virulent isolates. The primers used in the study were referred from Carbone and Kohn (1999) for actin and calmodulin, from Guerber et al. (2003) for GPDH and from Martinez-Culebras et al. (2003) for Colletotrichum specific ITS primers, coll and col2.

\section{Analysis with molecular markers}

\section{Random Amplification of Polymorphic DNA} (RAPD): Eight decamer oligonucleotide primers were used for the random amplification of red rot DNA with 6 RAPD primers (OPA 01, 03, 09, 15, 16 and 18) referred from earlier reports (Suman et al., 2005). PCR amplification was performed in a final volume of $20 \mu \mathrm{l}$ with $1 \mu \mathrm{l}$ of template DNA $\left(25 n g \mu 1^{-1}\right), 2 \mu 1$ of 10X PCR buffer, $1.6 \mu 1$ of dNTPs (2.5 mM of each of the dNTPs), $1 \mu 1$ of $\mathrm{MgCl}_{2}, 1 \mu \mathrm{l}$ of primer $(10 \mu \mathrm{M}), 1$ unit of Taq DNA polymerase and $13.07 \mu 1$ of Milli Q water. The DNA was amplified in a programmable thermal cycler with an initial denaturation step of $5 \mathrm{~min}$ at $94^{\circ} \mathrm{C}$ followed by 40 cycles of $1 \mathrm{~min}$ denaturation at $94^{\circ} \mathrm{C}, 2 \mathrm{~min}$ annealing (at $42^{\circ} \mathrm{C}$ for OPA03 and OPA $15,46^{\circ} \mathrm{C}$ for OPA 01 and $48^{\circ} \mathrm{C}$ for
OPA09, OPA16 and OPA18), 2 min at $72^{\circ} \mathrm{C}$ for extension. A final extension step was at $72^{\circ} \mathrm{C}$ for 5 min to ensure complete extension of the amplified products.

Inter Simple Sequence Repeats (ISSR). Eight ISSR primers (AF80820, AF80821, AF80822, AF80823, AF80824, AF80825, G5 and G6) previously reported for Colletotrichum (Ratanacherdchai et al., 2010) were used for the analysis of ISSR polymorphism among the red rot isolates. PCR amplification was performed in a final volume of $20 \mu \mathrm{l}$ with $1 \mu \mathrm{l}$ of template DNA (25 ng/ $\mu 1), 2 \mu 1$ of 10X PCR buffer, $1.6 \mu 1$ of dNTPs (2.5 mM of each of the dNTPs), $1 \mu \mathrm{l}$ of $\mathrm{MgCl}_{2}, 1 \mu \mathrm{l}$ of primer $(10 \mu \mathrm{M}), 1$ unit of Taq DNA polymerase and $13.07 \mu 1$ of Milli Q water. PCR conditions were 2 min initial denaturation at $94^{\circ} \mathrm{C}$ followed by 40 cycles of 1 min denaturation at $94^{\circ} \mathrm{C}, 1 \mathrm{~min}$ annealing (at $49^{\circ} \mathrm{C}$ for primer $\mathrm{AF} 80820,51^{\circ} \mathrm{C}$ for $\mathrm{AF} 80823,55^{\circ} \mathrm{C}$ for $\mathrm{AF} 8082$ and $\mathrm{AF} 80822,57^{\circ} \mathrm{C}$ for $\mathrm{AF} 80824$ and $59^{\circ} \mathrm{C}$ for $\mathrm{AF} 80825, \mathrm{G} 4$ and G5) and $1.5 \mathrm{~min}$ at $72^{\circ} \mathrm{C}$ for extension. A final extension step was carried out at $72^{\circ} \mathrm{C}$ for $6 \mathrm{~min}$.

Amplified PCR products were separated by electrophoresis on $1.5 \%$ agarose gel and the DNA bands were visualized under an ultraviolet transilluminator (AlphaImager, Alphainnotech, USA). Comparison of banding profile for each primer was carried out on the basis of presence (1) or absence (0) of the RAPD and ISSR products of the same size. Scoring has been done from the bands obtained from ISSR and RAPD analyses and phylogenetic tree has been constructed by using DARWIN 5-SINGLE software.

\section{Standardization on development of proteome profile of $C$. falcatum}

The representative isolates of virulent group (Cf671) and least virulent group (Cf94101) were used to standardize proteomic approach. For 
protein extraction, the isolates were grown on complete medium broth (CMB) for $72 \mathrm{~h}$ and the developing young mycelia before melanization was vacuum dried and used for protein extraction. Different protein extraction methods viz., acetone precipitation, TCA precipitation and acetone-TCA methods were attempted for protein extraction from fungal mycelia. In all the protocols, the mycelia were pulverized to a fine powder in a mortar and pestle with liquid nitrogen to minimize proteolysis and other modes of protein degradation. The quantitative protein yield in fungal mycelia was assessed in all the three methods of protein extraction. Acetone precipitation and TCA precipitation methods individually yielded much lower quantity of proteins. TCA/acetone precipitation method of protein extraction helped to remove non-protein contaminants and yielded higher concentration. After extracting the protein, the protein present in the sample was quantified by Bradford's method at an absorbance of $280 \mathrm{~nm}$ (Bradford 1976).

The protein extracts using above three protocols were subjected to SDS-PAGE and finally selected TCA/ Acetone precipitation method. The extracted protein was focussed on $18 \mathrm{~cm}$ ( $\mathrm{pH}$ 4-7) IPG strip, electrophoresed on 12\% SDS-PAGE and stained with CBB. This standardized protocol coincides with the procedure followed for the cane proteome profile (Amalraj et al., 2010) except the sample preparation. In this method, the mycelial proteins from both the isolates were precipitated by TCAacetone $(10 \% \mathrm{w} / \mathrm{v})$ method containing $0.07 \%$ DTT and the obtained pellet was washed with acetone and lyophilized. Then the proteins were solubilized in lysis buffer (7 M urea, $2 \mathrm{M}$ thiourea, 4\% w/v CHAPS, 2\% v/v IPG buffer $\mathrm{pH} 4-7$ and $0.3 \% \mathrm{w} / \mathrm{v}$ DTT), quantified using BSA as standard and the quality was checked in 12\% SDS-PAGE. Then $315 \mu \mathrm{l}$ of sample representing $\sim 600 \mu \mathrm{g}$ of protein was loaded in strip holder and passively rehydrated overnight onto $18 \mathrm{~cm}$ IPG strips, pI 4-7 (GE Healthcare). After rehydration, the strips were focused on EttanIPGphor II platform (GE Healthcare) until attaining a total of $45 \mathrm{kVh}$. The focused strips were reduced and alkylated by equilibrating twice (with 1\% DDT and 2.5\% iodoacetamide) for $20 \mathrm{~min}$ each in equilibration buffer containing $6 \mathrm{M}$ urea, 30\% (w/v) glycerol, $2 \%(\mathrm{w} / \mathrm{v}) \mathrm{SDS}$ and $50 \mathrm{mM}$ Tris- $\mathrm{HCl}$ buffer. Then the strips were subjected to $2^{\text {nd }}$ dimension in $12 \%$ SDS-PAGE gels with Tris-glycine buffer in EttanDALTsix Electrophoresis Unit (GE Healthcare). After the run was completed the gels were treated with fixing solution (40\% methanol, $10 \%$ acetic acid and $50 \%$ distilled water) for 30 min and stained with colloidal CBB solution (Kang et al. 2002) (0.02\% (w/v) CBB G-250, $5 \%(\mathrm{w} / \mathrm{v})$ aluminium sulfate hydrate, $10 \%(\mathrm{v} / \mathrm{v})$ ethanol $(96 \%)$ and $2 \%(\mathrm{v} / \mathrm{v})$ orthophosphoric acid ( $85 \%$ ) overnight. The stained 2D gels were digitalized in Image Scanner III (GE Healthcare) incompatible image formats (300dpi, 16bit, .tiff and .mel), the images were imported, warped and matched in ImageMaster2D Platinum version 7 software (GE Healthcare). Differentially abundant protein spots with statistical significance and protein spots exclusively present only in virulent isolate Cf671 were selected, picked manually and sent for MS analysis. Gel pieces were Coomassie destained and trypsin (Promega) digested. The digested peptides were subjected to MALDITOF using an AB Sciex 5800 TOF/TOF System, MALDI TOF TOF (Framingham, MA, USA). The obtained charge-mass ratio was analysed using MATRIX SCIENCE - MASCOT search software to identify the respective protein. 


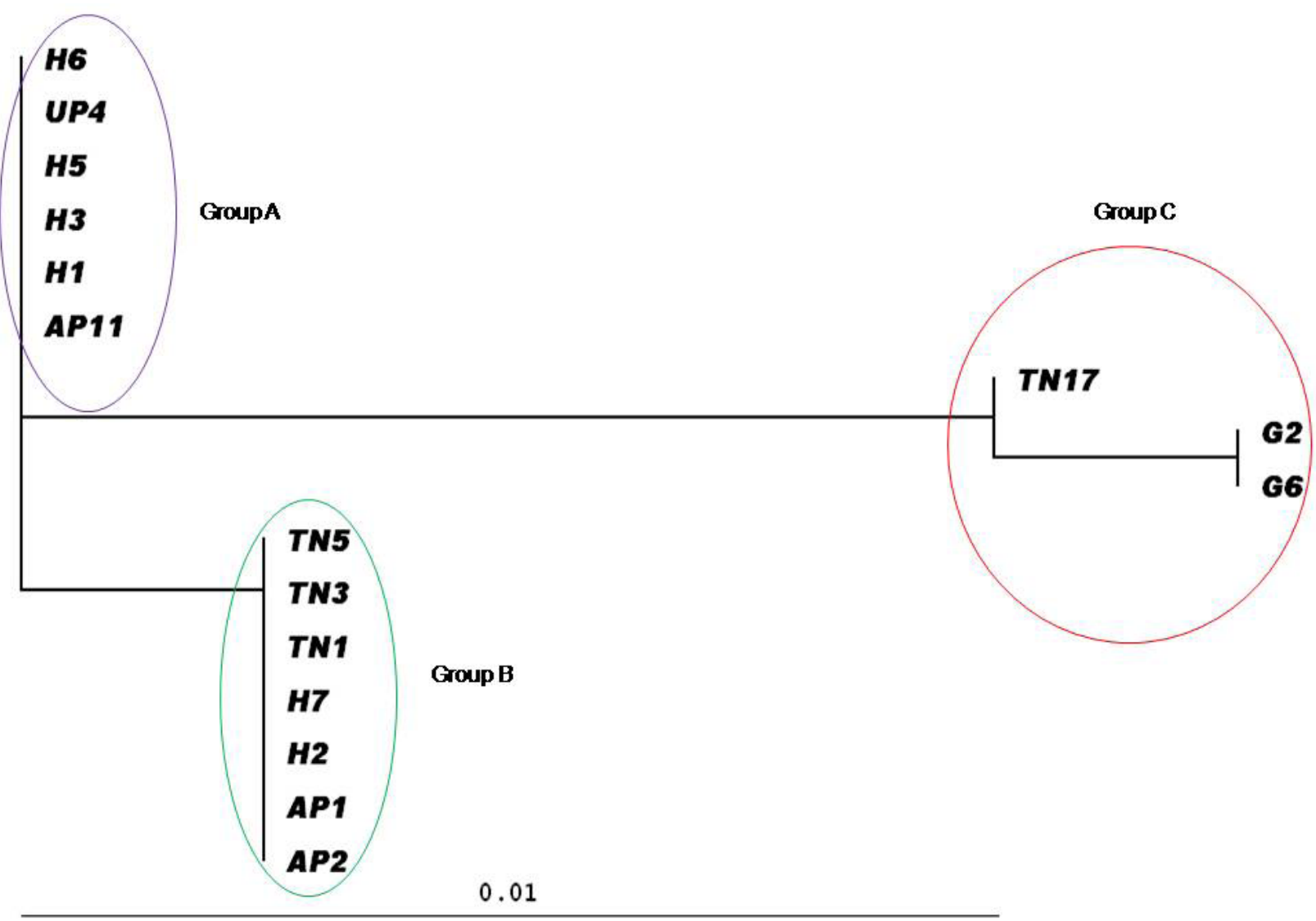

Fig. 1. Phylogenetic tree derived based on 5.8S ITS sequences of 16 Colletotrichum falcatum isolates

\section{Results and Discussion}

\section{Molecular analysis based on conserved gene sequences}

Phylogenetic analysis on 5.8S-ITS region of 16 C. falcatum isolates yielded three molecular groups (Fig. 1) as reported earlier (Malathi et al., 2011). Among the three groups, the first two groups were differentiated by $1 \mathrm{bp}$ and the third group was differentiated by $6 \mathrm{bp}$ as per our earlier report. Analysis on nucleotide sequence showed that there were 402 nucleotides including partial regions of ITS1 (127 bp) and ITS2 (96 bp) with complete sequence of 5.8S rDNA (179 bp) region. Though the primers could not yield complete ITS $1 \& 2$ regions, it was able to reveal all the variable regions of $C$. falcatum isolates. Previous studies also strongly recommend the use of rDNA sequence information for inferring phylogenetics and measuring genealogical relationship in Colletotrichum and analysis of ITS1 region provided more information for phylogenetic analysis than the ITS2 region (Martinz-Culebras et al., 2003; Whitelaw-Weckert et al., 2007). This confirms the present result of more variable ITS1 region in C. falcatum than ITS2.

Individual phylogenetic analyses of other three genes viz., actin, calmodulin and GPDH highly implicated the existence of Group III as in ITS analysis with high boot strap support, while movement of gene sequences between Group I and II were different (Results not shown). PCR amplification of actin gene with ACT-512F and ACT-783R yielded 253 bp product of $C$. 
M ITS Actin Calmodulin GPDH

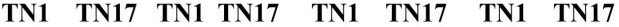

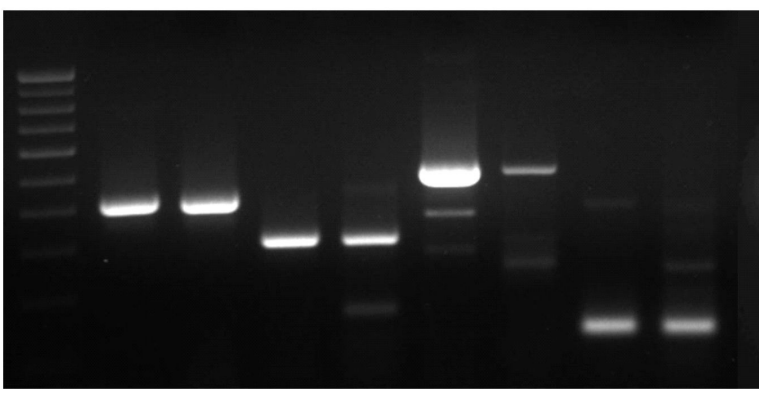

Fig. 2a. PCR amplification of 5.8S-ITS, Actin, Calmodulin and GPDH in Colletotrichum falcatum isolates varying in virulence falcatum. Like ITS, the nucleotide difference was 1 bp between Group I \& II and Group III was distinguished by $5 \mathrm{bp}$ and confirmed the least virulent isolates in Group C. However, movement of isolates between first two groups were different. Similarly, the calmodulin sequence of 485 bp also differed among $C$. falcatum isolates, wherein only $1 \mathrm{bp}$ differentiated the Group I from Group II and the Group III has 4 variable nucleotides from others. Further sequence analysis of GPDH intron of $152 \mathrm{bp}$ showed only two groups by separating least virulent group with $1 \mathrm{bp}$ difference from

ITS - 6 nucleotide variation

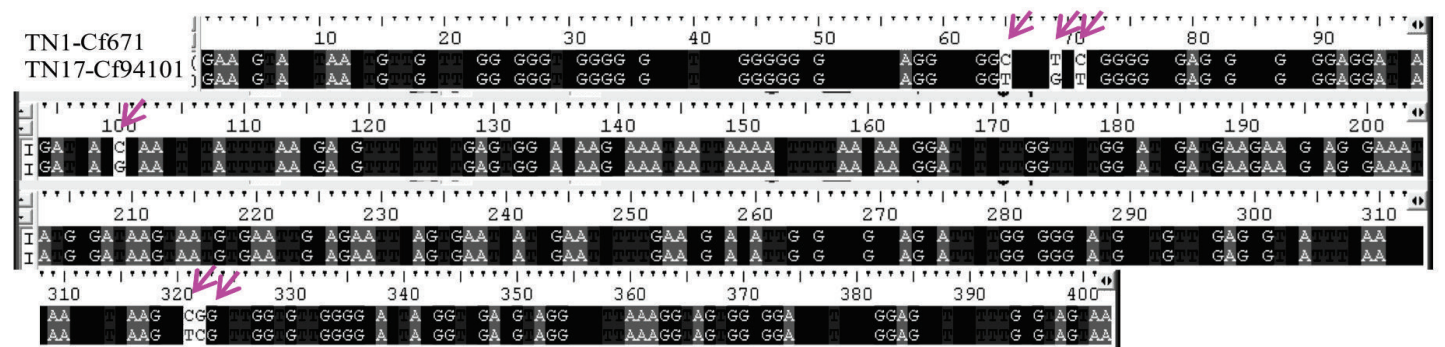

Actin - 5 nucleotide variation

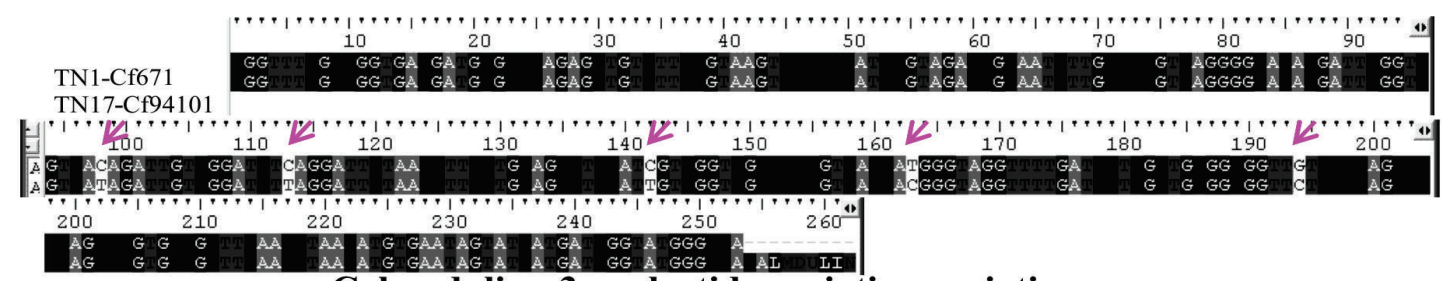

Calmodulin - 3 nucleotide variation variations

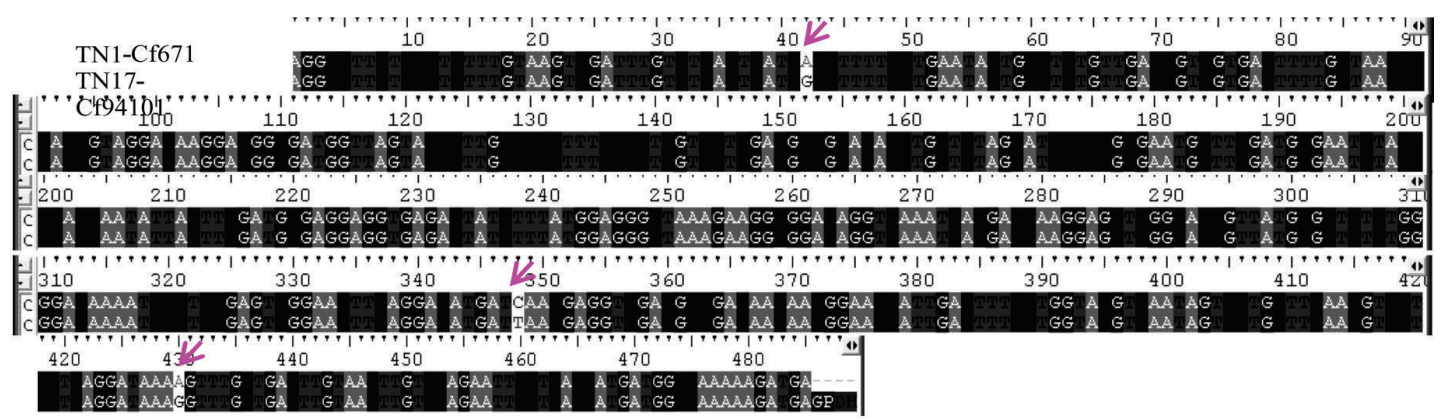

GPDH - 1 nucleotide variation

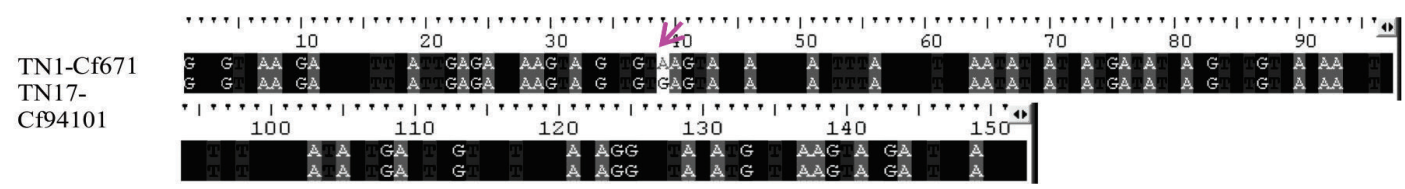

Fig. 2b. Variation in conserved gene sequences of highly virulent and least virulent isolates of Colletotrichum falcatum 
virulent group. Based on all these results, the nucleotide sequences of four conserved genes of virulent pathotype TN1 and least virulent isolate TN17 were amplified with respective primers (Fig. 2a) and the sequence variation has been shown (Fig. 2b). Evidences were available on the use of GPDH gene sequences in phylogenetics of ascomycetous and basidiomycetous fungi (Kruezinger et al. 1996) and at intra-species level for C. acutatum grouping (Guerber et al. 2003). Templeton et al. (1992) characterized this gene with coding and non-coding regions in Glomerella cingulata. The other two loci actin and calmodulin were exceedingly used in delineating speciation of Magnaporthe sp (Cough and Kohn 2002; Hirata et al. 2007). 5.8S-ITS and $\beta$-tubulin gene sequences have been widely used to study the phylogenetic relationships in correlation with pathogenicity and other groupings of various Colletotrichum spp. causing anthracnose in various crops (WhitelawWeckert 2007).

\section{Molecular grouping based on genetic markers}

All the 10 pathotypes and 6 isolates were subjected to RAPD and ISSR analysis and grouped them accordingly. Both the markers confirmed the existence of the minor group (Fig. 3a \& 3b) and grouped other isolates and pathotypes into two groups with some contradictions among them.

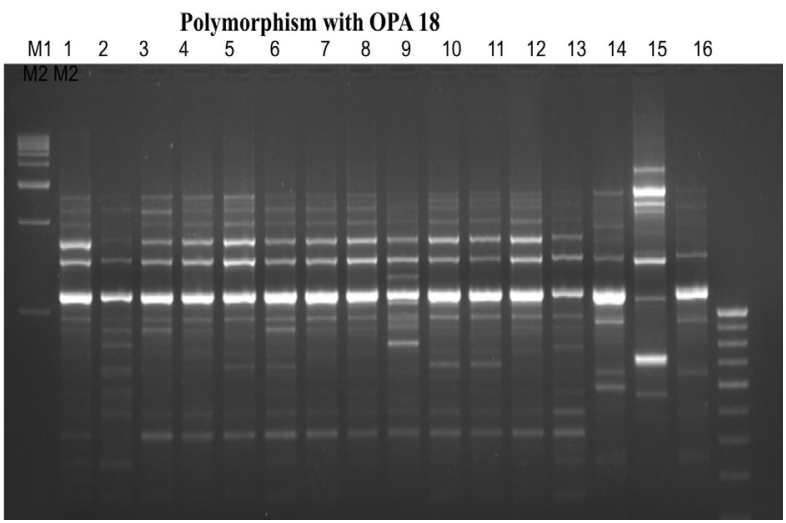

Fig. 3a. Profile of 16 Colletotrichum falcatum isolates generated by RAPD primer OPA 18
However they confirmed the similarity of tropical isolates/ pathotypes particularly from Tamil Nadu (TN1,TN3 and TN5) and Andhra Pradesh (AP1 and AP2) in one group along with $\mathrm{H} 2$ and $\mathrm{H} 7$ from Haryana. While $\mathrm{H} 1$ was in another group along with most of the sub-tropical isolates and incompatibility of $\mathrm{H} 1$ and $\mathrm{H} 2$ was shown by keeping them in separate groups. It supports the results of Mohanraj et al. (2002) who concluded that subtropical pathotypes $\mathrm{H} 2$ and $\mathrm{H} 1$ were widely distinct while the tropical pathotype TN1 and the isolate TN3 exhibited closest genetic relationship among the isolates studied. This was also further confirmed by vegetative compatibility grouping and ITS gene based sequences (Malathi et al. 2010). Suman et al. (2005) examined for genetic relationships using RAPD markers among six $C$. falcatum pathotypes prevalent in the subtropical India and reported existence of two groups among sub-tropical pathotypes with $\mathrm{H} 1$ and $\mathrm{H} 2$ in two different clusters. Of the two analyses in the present study, ISSR primers clearly confirmed the existence of ITS based Group III isolates in a separate group and grouped the isolates/ pathotypes based on their origin and virulence nature to some extent (Fig. 4).

Results of our present study revealed that ISSR primers are highly reliable in understanding the

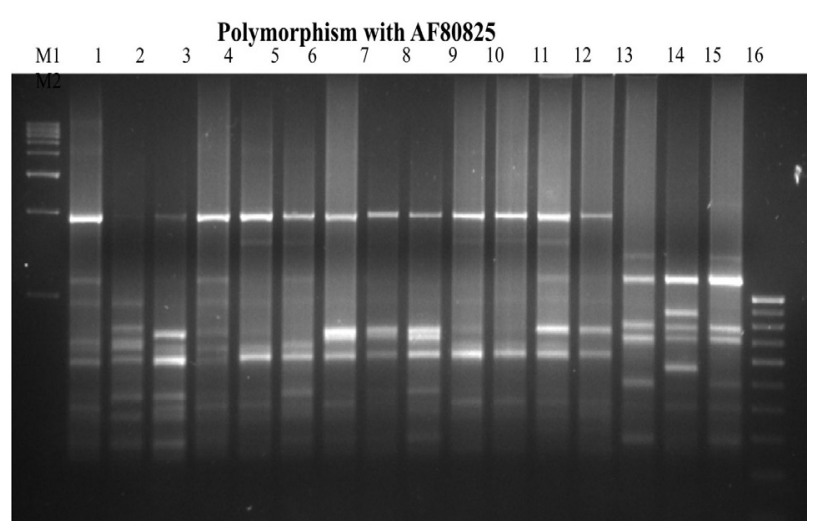

Fig. 3b. Profile of 16 Colletotrichum falcatum isolates generated by ISSR primer AF 80825 


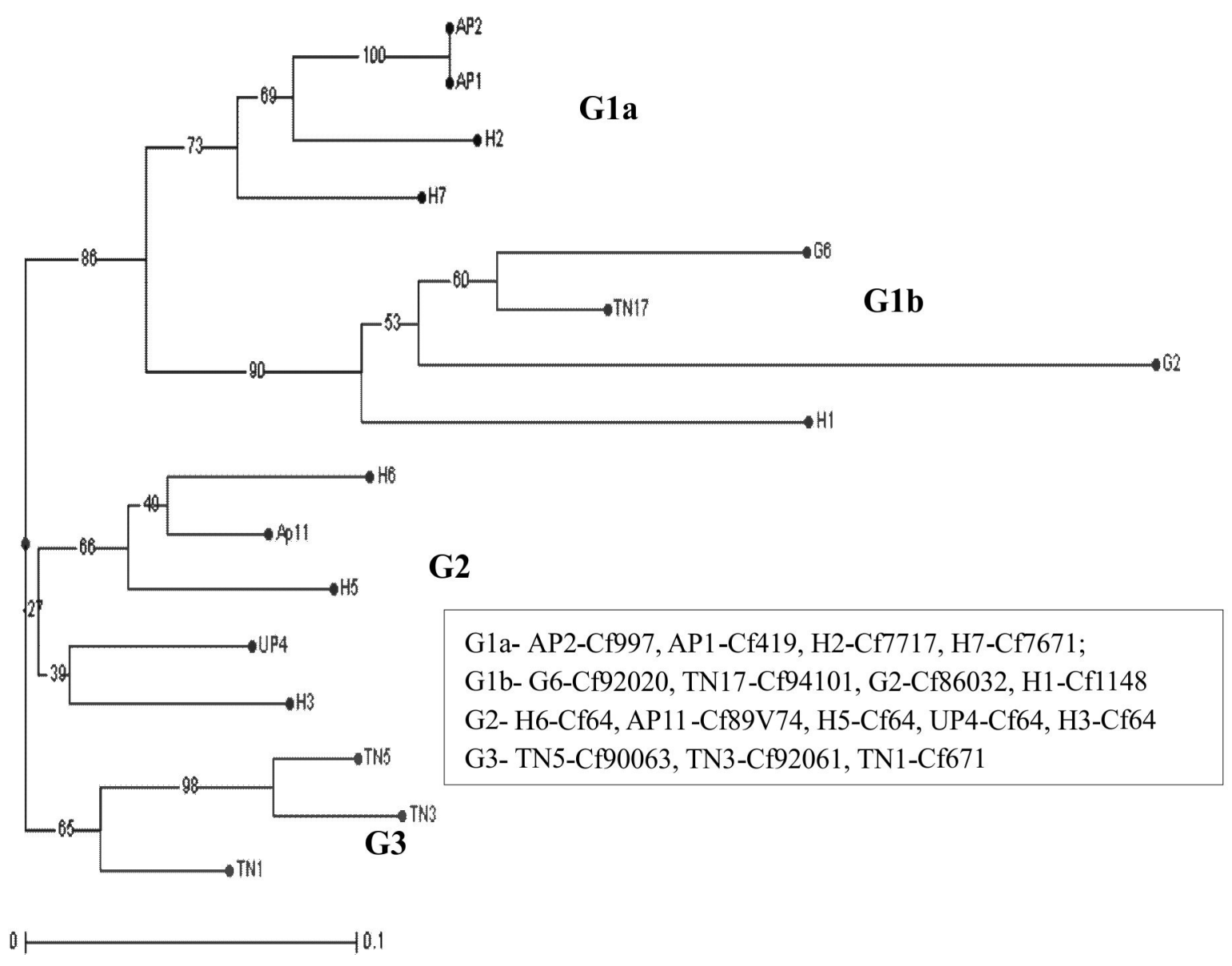

Fig. 4. Phylogenetic tree derived from 8 ISSR finger prints of 16 Colletotrichum falcatum isolates

evolutionary relationship and also the virulence pattern of C. falcatum isolates, although RAPD could confirm some of the results. Reports available indicated that ISSR markers were widely used to characterize the fungal populations and the potential of ISSR primers in understanding the phylogenetic relationship of fungi was shown by various workers. Studies of Ratanacherdchai et al. (2010) with ISSR analysis in chilli anthracnose pathogen indicated that there are two distinct groups of C. gloeosporioides and C. capsici. Furthermore, genetic diversity was correlated with geographic distribution, while no clear relationship between genetic diversity and pathogenic variability was established. Likewise, pathogenic and molecular variability have been studied with regional specific isolates using molecular markers (RAPD, URP and ISSR) and ITS-RFLP analyses. However, they could not obtain any tangible results (Mishra and Behera 2009; Kumar et al. 2010).

\section{Development of $C$. falcatum proteome profiles to differentiate $\boldsymbol{C}$. falcatum isolates}

In the present study, the 2-DE profiles showed a total of 449 spots in CF06 and 427 spots in Cf94101, which indicates a critical difference for number of spots between them (Fig. 5). The two profiles were analysed using Image Master 2D Platinum 7 software and 294 matching spots were identified. The remaining unmatched spots probably considered as unique spots for the respective strains. Randomly eight spots were analysed by MALDI-TOF and subsequent mass 

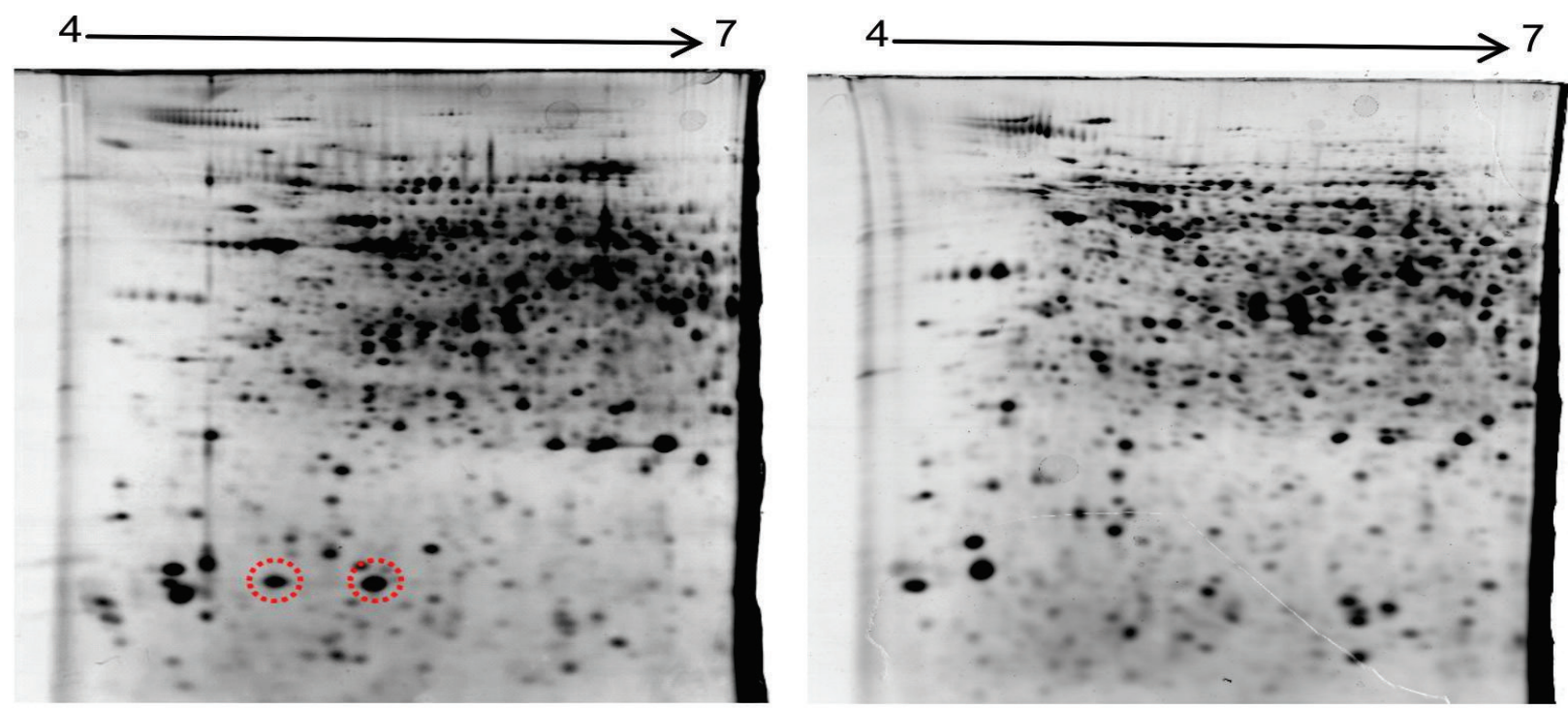

\section{$\mathrm{pH}-4-7,18 \mathrm{~cm}$ IPG strip}

Fig. 5. Proteome profiles of virulent (left) and least virulent (right) isolates

data search in MASCOT identified the spots as galactokinase, serine protease, protease subunit alpha, phospho pyruvate hydratase, Bys1 family protein mRNA, hypothetical protein partial mRNA, DJ-1/PfpI family protein partial mRNA and glutathione S-transferase domain-containing protein partial mRNA. Among these proteins, serine protease (Muszewska et al. 2017), DJ-1/ PfpI family protein (Chu et al. 2015;) and glutathione S-transferase (Calmes et al. 2015) act as virulent factors for fungal pathogens, while protease subunit alpha acts as ubiquitin dependent catabolic protein involved in lysis of host defense proteins (Pan et al. 2013) and Bys1 family protein (Ashwin et al. 2017) was reported to be involved in sporulation.

Proteome profiles developed in this study for two C. falcatum pathotype/ isolate clearly demonstrated the greater possibility of this approach for studying pathogen variability and further applicability of pathogenicity related genes identification. In Botrytis cinerea, the mycelial 2-DE protein profile revealed the existence of qualitative and quantitative differences between the analyzed strains based on virulence and most of the identified proteins were malate dehydrogenase (MDH) and glyceraldehyde-3-phosphate dehydrogenase (GAPDH) (Ferna'ndez-Acero et al. 2007). Likewise, many reports were available on proteins involved in pathogenicity process of various fungi. Recently, Gonzalez Fernandez et al. (2014) identified malate dehydrogenase or peptidyl-prolylcis-trans isomerase from the mycelium, and endopolygalacturonase, aspartic protease orcerato-platanin protein from the secretome and have been reported as virulence factors, which are involved in host-tissue invasion, pathogenicity or fungal development of the necrotrophic fungus Botrytis cinerea. Similarly, comparative secretome analysis of $C$. falcatum by a Ashwin et al. (2017) identified a pathogen-associated molecular pattern (PAMP) and its functional characterization showed a major cerato-platanin domain (EPL1 $\Delta \mathrm{N1}-92$ ) which is a defense inducing and hypersensitive response (HR) agent in sugarcane and tobacco, respectively.

Results from the study based on conserved gene sequences clearly indicated that the existing 
pathotypes/ isolates of $C$. falcatum have least genetic variation and exhibits monophyletic origin except for confirming the least virulent isolates. However, selection of phylogenetically differentiated virulent and least virulent isolates for proteomic study will be highly helpful in identification and characterization of pathogenicity/ virulence related genes involved in C. falcatum pathogenesis. Hence, the pathogenic variation could be attributed to the adoption of existing isolates to the newer cultivars resulting in co-evolution of new variants of the pathogen, which has been proved in our earlier study with cross inoculation of incompatible pathotypes (Malathi et al. 2006). Recent study very clearly elaborated on evolution of a new pathotype CF12 of C. falcatum from the tropical region in India from the virulent pathotype CF06. The new pathotype has acquired further virulence to knockdown the recently introduced varieties for cultivation by the acquired virulence (Viswanathan 2017).

\section{Conclusion}

Results revealed that the ISSR based markers probably differentiate the isolates based on virulence and it needs further detailed study with large number of isolates using selected markers from this study. The present study forms the basis to study further on confirming new isolates using conserved gene sequences, identifying virulence related markers based on ISSR profiles from a large group of isolates and proteomic based analysis of phylogenetically differentiated isolates to characterize differentially expressed gene/ proteins in relation to virulence.

\section{Acknowledgement}

The authors are grateful to the Director, ICARSugarcane Breeding Institute for providing facilities and constant encouragement.

\section{References}

Alfaro M, Oguiza JA, Ramírez L, Pisabarro AG (2014) Comparative analysis of secretomes in basidiomycete fungi. Journal of Proteomics 102: 28-43.

Amalraj RS, Selvaraj N, Veluswamy GK, Ramanujan RP, Muthurajan R, Palaniyandi M, Agrawal GK, Rakwal R, Viswanathan R (2010) Sugarcane proteomics: Establishment of a protein extraction method for 2-DE in stalk tissues and initiation of sugarcane proteome reference map. Electrophoresis 31: 1959-1974.

Ashwin NMR, Barnabas L, Sundar AR, Malathi P, Viswanathan R, Masi A, Agrawal GK, Rakwal R (2017) Comparative secretome analysis of Colletotrichum falcatum identifies a cerato-platanin protein (EPL1) as a potential pathogen-associated molecular pattern (PAMP) inducing systemic resistance in sugarcane. Journal of Proteomics 169: 2-20.

Bradford M (1976) A Rapid and sensitive method for the quantitation of microgram quantities of protein utilizing the principle of proteindye binding. Analytical Biochemistry 72: 248-254.

Calmes B, Morel-Rouhier M, Bataillé-Simoneau N, Gelhaye E, Guillemette T, Simoneau $P$ (2015) Characterization of glutathione transferases involved in the pathogenicity of Alternaria brassicicola. BMC M icrobiology 15(1): 123.

Carbone I, Kohn LM (1999) A method for designing primer sets for speciation studies in filamentous ascomycetes. Mycologia 91: 553-556.

Chu J, Li WF, Cheng W, Lu M, Zhou KH, Zhu HQ, Li FG, Zhou CZ (2015) Comparative analyses of secreted 
proteins from the phytopathogenic fungus Verticillium dahliae in response to nitrogen starvation. Biochimica et Biophysica Acta (BBA)-Proteins and Proteomics 1854(5):437-448.

Cough BC, Kohn LM (2002) A multilocus gene genology concordant with host preference indicates segregation of new species Magnoporthe oryzae from M. grisea. Mycologia 94(4): 683-693.

Fernández-Acero FJ, Jorge I, Calvo E, Vallejo I, Carbú M, Camafeita E, Garrido C, López JA, Jorrin J, Cantoral JM (2007) Proteomic analysis of phytopathogenic fungus Botrytis cinerea as a potential tool for identifying pathogenicity factors, therapeutic targets and for basic research. Archives of Microbiology 187(3): 207-15.

González-Fernández RK, Aloria RK, ValeroGalván J, Redondo I, Arizmendi JM, Jorrín-Novo JV (2014) Proteomic analysis of mycelium and secretome of different Botrytis cinerea wild-type strains. Journal of Proteomics 97:195-221.

Guerber JC, Liu BCorrell C, Johnston PR (2003) Characterization of diversity in Colletotrichum acuttumsensulato by sequence analysis of two introns, mtDNA and intron RFLPs and mating compatibility. Mycologia 3: 872-895.

Hirata K, Kusaba M, Chusm I, Osu J, Nakayashiki H, Mayama S, Tosa Y (2007) Speciation in Pyricularia inferred from multilocus phylogenetic analysis. Mycological Research111: 799-808.

Kang D, Gho YS, Suh M, Kang C (2002) Highly Sensitive and fast protein detection with coomassie brilliant blue in sodium dodecyl sulfate-polyacrylamide gel electrophoresis. Bulletin of Korean Chemical Society 23(11): 1511.
Kaverinathan K, Scindiya M, Malathi P, Viswanathan R, Sundar AR (2017) Role of melanin in Colletotrichum falcatum pathogenesis causing sugarcane red rot. Sugar Tech 19(6): 584-591.

Kreuzinger N, Podeu R, Gruber F, Gobl Kubicek CP (1996) Identification of some ectomycorrhizalbasidiomycetes by PCR amplification of their gpd (Glyceraldehyde3-Phosphate Dehydrogenase) genes. Applied and Environmental Microbiology 62: 3432-3438.

Kumar N, Jhang T, Sharma TR (2010) Molecular and pathological characterization of Colletotrichum falcatum infecting subtropical Indian sugarcane. Journal of Phytopathology 159(4): 260-267.

Malathi P, Viswanathan R, Jothi R (2006) Specific adaptation of Colletotrichum falcatum pathotypes to sugarcane cultivars. Sugar Tech 8(1): 54-58.

Malathi P, Viswanathan R, Ramesh Sundar A, Prakasam N, Padmanaban P, Jothi R, Renuka Devi SR, Poongothai M (2010) Variability among Colletotrichum falcatum pathotypes used for screening red rot resistance in sugarcane. Sugar Cane International 28: 47-52.

Malathi P, Viswanathan R, Ramesh Sundar A, Padmanaban P, Prakasam N, Jothi R (2011) Phylogenetic analysis of Colletotrichum falcatum isolates causing red rot in sugarcane. Journal of Sugarcane Research 1: 69-74.

Malathi P, Viswanathan R (2012) Identification of pathogenicity determinants in Colletotrichum falcatum using wild and mutant cultures. Sugar Tech 14(4): 383390.

Martinz-Culebras PV, Querol A, Surez-Fernandez MB, Garcia-Lopez MD, Barrio E (2003) 
Phylogenetic relationships among Colletotrichum pathogens of strawberry and design of PCR primers for their identification. Journal of Phytopathology 151: 135-143.

Mishra MK, Behera B (2009) Pathogenic and molecular variability of Colletotrichum falcatum Went. isolates from sugarcane with red rot disease symptoms. Journal of Crop Science and Biotechnology 12(1) : 31-35.

Mohanraj D, Kumaresan S, Sreenivasan TV (2002) Molecular characterization of isolates of the sugarcane red rot pathogen Colletotrichum falcatum Went. Indian Phytopathology 55(2): 147-151.

Muszewska A Stepniewska-Dziubinska MM, Steczkiewicz K, Pawlowska J, Dziedzic A, Ginalski K (2017) Fungal lifestyle reflected in serine protease repertoire. Scientific Reports 7: 9147.

Pan X, Zhu B, Luo Y, Fu D (2013) Unraveling the protein network of tomato fruit in response to necrotrophic phytopathogenic Rhizopus nigricans. PloS one 8(10): 1371.

Ratanacherdchai K, Wang HK, Lin FC, Soytong K (2010) ISSR for comparison of crossinoculation potential of Colletotrichum capsici causing chilli anthracnose. African Journal of Microbiological Research 4(1): 076-083.

Scindiya M, Malathi P, Kaverinathan K, Viswanathan R, Sundar AR (2017) Molecular characterization of pathogenicity gene homologs in Colletotrichum falcatum causing red rot in Sugarcane. Sugar Tech 19(6): 563-572.
Suman A, Sunita Lal, Shasany AK, Asha Gaur, Singh P (2005) Molecular assessment of diversity among pathotypes of Colletotrichum falcatum prevalent in subtropical Indian sugarcane. World Journal of Microbiology and Biotechnology 21: 11351140.

Templeton MD, Rikkerink EH, Solon SL, CrowhurstRN(1992)Cloning and molecular characterization of the glyceraldehydes3-phosphate dehydrogenase -encoding gene and cDNA from the plant pathogenic fungus Glomerella cingulata. Gene 122: 225-230.

Viswanathan R (2010) Plant Disease: Red Rot of Sugarcane. Anmol Publishers, New Delhi India. p306.

Viswanathan R (2017) Pathogen virulence in sugarcane red rot pathogen versus varieties in cultivation: Classical case of loss in virulence in the pathotype CF06 (Cf671). Sugar Tech 19: 293-299.

Viswanathan R, Malathi P, Padmanaban P (2003) Variation in sugarcane red rot pathogen Colletotrichum falcatum Went. In: Frontiers of Fungal Diversity in India (Eds Rao GP Manoharachari C Bhat DJ Rajak RC Lakhanpal TN). International Book Distributing Co Lucknow. 639-667.

Whitelaw-Weckert MA, Curtin SJ, Haung R, Steel CC, Blanchard CL, Roffey PE (2007) Phylogenetic relationships and pathogenicity of Colletotrichum acutatum isolates from grape in subtropical regions. Australia. Plant Pathology 56: 448563. 